wissenschaftlichen Fachzeitschriften findet man auch in ARNolds Bücherkunde, den neuesten Stand gibt JohanNes HaNSEL Bücherkunde für Germanisten an. Im übrigen kann man auf die allgemeinen Bücherverzeichnisse verweisen, die die Zeitschriftentitel selbstverständlich auch nennen.

\title{
III. Das Nachschlagen von Realien
}

Nachdem im darstellenden Teil die wenigen zu Gebote stehenden allgemeinen Hilfsmittel der literaturwissenschaftlichen Forschung genannt wurden, kann hier auf eine Benutzungsanweisung verzichtet werden. Der "Merker-Stammler", zum Teil in 2. Auflage wird zu jeder sachlichen Ermittlung unentbehrlich sein, so wie die definierenden kurzgefaßten Sachwörterbücher ( $\mathrm{Nr}$ 142, 143). Man kann diese durch die neuesten Allgemeinenzyklopädien, die meist fundierte Artikel bringen, ergänzen. Auch der »Kosch« kann zuweilen hier hilfreich sein.

Stets zur Hand müssen die wichtigsten, genannten Literaturgeschichten sein, sie leisten beim Nachschlagen den Dienst erster Orientierung. Zur Information über einzelne Werke empfiehlt es sich, Romanführer und Dramenführer anzusehen.

Den Ausflug in Nachbardisziplinen beginne man auch bei den Allgemeinenzyklopädien, ziehe dann die Reallexika einzelner Wissenschaftszweige heran, auch einführende Werke, die man häufig schon im "Brockhaus« angegeben findet.

\section{Die Ermittlung biographischer Angaben}

Auf der Suche nach biographischen Mitteilungen zu einem Autor kann man eine Reihe biographischer und bio-bibliographischer Hilfsmittel benutzen, die oft schon eine erschöpfende Auskunft geben oder aber in den Anmerkungen weitere Literatur vermerken.

TABELLE $\mathrm{I} 3$

Wie aus Tabelle I 3 ersichtlich wird, steht obenan die Allgemeine Deutsche Biographie mit der Neubearbeitung in der Neuen 